\title{
Venous retinal flow reperfusion mechanisms following radial optic neurotomy with adjunctive intraocular triamcinolone in central retinal vein occlusion
}

\author{
Pina Fortunato • Liliana Pollazzi • Maurizio Baroni • \\ Attilio Evangelisti • Agostino La Torre
}

Received: 31 March 2009 /Revised: 21 July 2009 /Accepted: 20 August 2009 /Published online: 16 September 2009

(C) The Author(s) 2009. This article is published with open access at Springerlink.com

\begin{abstract}
Background To evaluate retinal reperfusion, anastomosis, and compensation following radial optic neurotomy for ischemic nonperfused central retinal vein occlusion.

Methods Prospective, non-comparative, interventional case series of 13 patients with ischemic, nonperfused central retinal vein occlusion underwent decompression surgery with a radial optic neurotomy and adjunctive intraocular triamcinolone. Patients were followed for 1 year after
\end{abstract}

The authors have no financial or proprietary interest.

P. Fortunato $\cdot$ A. La Torre

Department of Surgical Oto-Neuro-Ophthalmology Sciences,

University of Florence,

Viale Morgagni,

85-50134 Florence, Italy

P. Fortunato

e-mail: pinfor@tin.it

A. La Torre

e-mail: agostino.latorre@unifi.it

L. Pollazzi $(\square)$

PO Box 30-50032, Borgo San Lorenzo,

Florence, Italy

e-mail: liliana.po@libero.it

M. Baroni

Department of Electronics and Telecommunications,

University of Florence,

Via S. Marta,

3-50134 Florence, Italy

e-mail: maurizio.baroni@unifi.it

\section{A. Evangelisti}

Department of Systems and Computer Science,

University of Florence,

Via S. Marta,

3-50134 Florence, Italy

e-mail: attilio.evangelisti@unifi.it surgery, and were analyzed in the preoperative and postoperative stages determining: visual acuity by ETDRS chart (LogMar) and retinal thickness with optical coherence tomography. Fluorescein angiography was performed at regular intervals to evaluate the capillary perfusion grade. Intraocular pressure was measured and fundus was examined.

Results Visual acuity and retinal thickness improved in 10/13 (77\%) patients after surgery at 1-year follow-up. Adequate retinal reperfusion was achieved in ten of the 13 eyes. Acute reperfusion occurred in six eyes within 2 weeks of surgery and a shunt vessel at the optic disk developed in four eyes within 4 months. In the remaining three eyes, retinal reperfusion was not observed by fluorescein angiography. No complications were noted in any of the patients.

Conclusion Surgical decompression promoted mechanical reperfusion of the occluded vessel in 10/13 (77\%) cases. In $6 / 13$ patients $(46 \%)$ reperfusion occurred within 2 weeks of surgery, and in $4 / 13$ patients $(31 \%)$ collateral vessels formed within 4 months.

Keywords Central retinal vein occlusion $\cdot$ Radial optic neurotomy $\cdot$ Anastomosis

\section{Introduction}

Among patients with central retinal vein occlusion (CRVO), 34\% develop capillary nonperfusion and retinal ischemia with at least ten disc areas of nonperfusion [1]. Iris neovascularization and neovascular glaucoma occur in 45 to $85 \%$ of eyes affected by ischemic CRVO and in only $5 \%$ of initially non-ischemic CRVO [2]. Until recently, there has been no effective treatment for CRVO confirmed 
by multicentric studies. Visual function may be seriously and permanently damaged without appropriate treatment.

The etiology and pathogenesis of CRVO, a multifactorial retinal vascular disease [3], are not yet understood [4], although histopathologic studies suggest that the lamina cribrosa is the site of thrombus formation. Histopathologic studies performed on enucleated eyes due to CRVO between 1974 and 1979 by Green et al. [5], with a 6-year follow-up, indicated that a thrombus site in CRVO was at or behind the lamina cribrosa in 24 of 29 eyes, with the thrombus located in front of the lamina cribrosa in only five eyes. Opremcak et al. $[6,7]$ reported the importance of the optic disk anatomy in the lamina cribrosa area for CRVO. In their opinion, the narrow passage at which the optic nerve diameter shrinks to $1.5 \mathrm{~mm}$ is the area of hemodynamic turbulence that leads to thrombus formation, and the anatomic alterations that create an optic nerve bottleneck justify a surgical approach for treating central vein occlusion.

Medical therapy is often disappointing, as only those hemodynamic parameters that lead to complications (increased blood viscosity and hypertension) can be modified, and it is rarely effective for inducing reperfusion. As reported by the Central Vein Occlusion Study [8, 9], laser treatment (panretinal, focal, or grid) can stop retinal and iris neoangiogenesis, but has little effect on improving visual acuity (VA). The recent use of anti-vascular endothelial growth factor and anti-inflammatory drugs provide pending results as of today, because no large-scale prospective trial has been published.

In the present study, we evaluated the validity of Opremcak's technique and examined the mechanisms involved in retinal perfusion.

\section{Materials and methods}

A prospective, non-comparative, interventional case series was designed to evaluate the outcome of radial optic neurotomy (RON) in 13 patients with nonperfused central retinal vein occlusion, defined angiographically as eyes with ten disc areas or more of retinal capillary nonperfusion [10]. We have enrolled only patients without large areas of hemorrhage in the periphery of the retina, but we have included patients with large hemorrhage around the optic nerve.

The 13 patients were all older than 60 years of age (69.8 \pm 6.7$)$ with CRVO occurring within the previous 12 months and a preoperative VA of $\leq 0.1$ LogMar, without neovascularization or neovascular glaucoma and posterior vitreous already detached before surgery, confirmed by ophthalmoscopic observation with Goldmann Lens. No patients had received any previous treatment with anti-
VEGF or corticosteroid drugs before surgery. The reperfusion of the occluded venous vessel, the decrease in capillary venous transit time and the decrease of tortuosity, were in our opinion a successful result.

VA and intraocular pressure were measured in all patients. Fundus examination (including the retinal periphery), fluorescein angiography (to establish perfusion state), and optical coherence tomography (OCT3 Stratus) for evaluating foveal depression and retinal thickness were performed preoperatively and postoperatively. Patients were followed for 1 year postoperatively, and each of these examinations was repeated at 1 week postoperatively and then monthly. Fluorescein angiography was performed once a month for the first 2 months, then every 4 months. In only one of the four patients with anastomosis we performed an ICG angiography to show the drainage routes into retinochoroidal collateral circulation. Visual field testing (Humphrey 24-2) was performed preoperatively and at 8 months after RON in patients with normal fixation.

All patients provided informed consent, and Ethics Committee approval was obtained. The study protocol adhered to the tenets of the Declaration of Helsinki. To eliminate the effect of variations in technique and data collection, all surgeries were performed by a single surgeon. Standard surgical techniques were used to perform pars plana vitrectomy, as follows. The central vitreous cone was carefully removed up to the insertion of the optic nerve to eliminate possible residual vitreoretinal adhesions from the vascular peduncle emerging from the disk, although vitreous detachment had already occurred before surgery. The perfusion pressure was increased to reduce the risk of bleeding at the moment of incision, which was made using a CRVO blade (Synergetics, Inc., St. Charles, MO, USA) designed to safely and accurately cut around the optic nerve. The sharp edge of the calibrated blade (two-sided asymmetric blade: sharp/blunted) was directed at the avascular portion of the nasal-side margin of the optic disk, and the incision edges were spread to decompress the vessels by making small rotatory movements on the blade axis. The nasal side of the optic disk was selected to avoid the risk of injury to the maculopapillary nerve fibers. The incision was made radial to the nerve and parallel to the nerve fiber layer to avoid the major vessels.

When the surgical maneuver was completed, before the blade was extracted, the perfusion pressure was decreased to physiologic pressure conditions $(18-20 \mathrm{mmHg})$. In the case of hemorrhage, the pressure was increased and the maneuver was repeated until hemorrhage stopped. Then, the blade was extracted. At the end of the surgery, triamcinolone acetonide (KENACORT ${ }^{\circledR} ; 4 \mathrm{mg} / 0.1 \mathrm{ml}$ ) was injected into the vitreous cavity. Neither intraoperative laser photocoagulation nor gas tamponade was used in any 
of the cases. The internal limiting membrane was not peeled in any of the patients.

\section{Results}

The preoperative and postoperative fluorescein angiography and OCT results are shown in Figs. 1, 2, and 3. Demographic data are reported in Table 1 with measured data of visual acuity and retinal thickness of all 13 patients. To investigate the difference between pre-operative and post-operative data, a standard $t$-test was performed using a significance level of $5 \%$.

In the first place, visual acuity values showed a significant difference after surgery $(p<0.05)$ (Fig. 4). It is important to stress that not one of the 13 patients experienced a worsening in VA, not even those patients $(3 / 13,23 \%)$ where retinal reperfusion after RON was not achieved. Best-corrected visual acuity, with an average gain of five Snellen lines, was observed in 4/13 (31\%) patients, where an anastomosis appeared at the RON incision site. The remaining 6/13 $(46 \%)$ patients gained at least two Snellen lines.

Secondarily, a statistically significant difference between pre- and post-operative retinal thickness values was found $(p<0.01)$ (Fig. 5), showing a decrease of macular edema in all 13 patients (100\%) within 1 month of surgery, probably due to the anti-edemagenic action of Triamcinolone [11].

In three of the 13 patients $(23 \%)$, retinal reperfusion was not observed with fluorescein angiography during the 1 year of follow-up. In contrast, reperfusion was achieved in ten of 13 patients $(77 \%)$ with resolution of the vessel tortuosity and macular edema, documented by fluorescein angiography and OCT. In six of these 13 patients $(46 \%)$, reperfusion occurred immediately, and was complete within 2 weeks after surgery. Despite reperfusion after 30 days, three of these six patients (50\%) developed recurrent macula edema, which was treated with a grid laser and regressed completely after

Fig. 1 Patient 3. a Preoperative fluorescein angiography showing marked edema of the optic disc and venous stasis. b Preoperative foveal thickness measured by optical coherence tomography was $920 \mu \mathrm{m}$. Macular edema and serous detachment of the neuroepithelium. Preoperative VA was 0.7 (LogMar). c Postoperative fluorescein angiography 2 months after surgery showing decreased edema and venous stasis. d Postoperatively, foveal thickness decreased to $270 \mu \mathrm{m}$, the macular edema disappeared, and the serous detachment was reduced. Postoperative VA was 0.1 (LogMar). e,f Fluorescein angiography and indocyanine green angiography 4 months after surgery showed the anastomosis at the nasal neurotomy site (arrow)
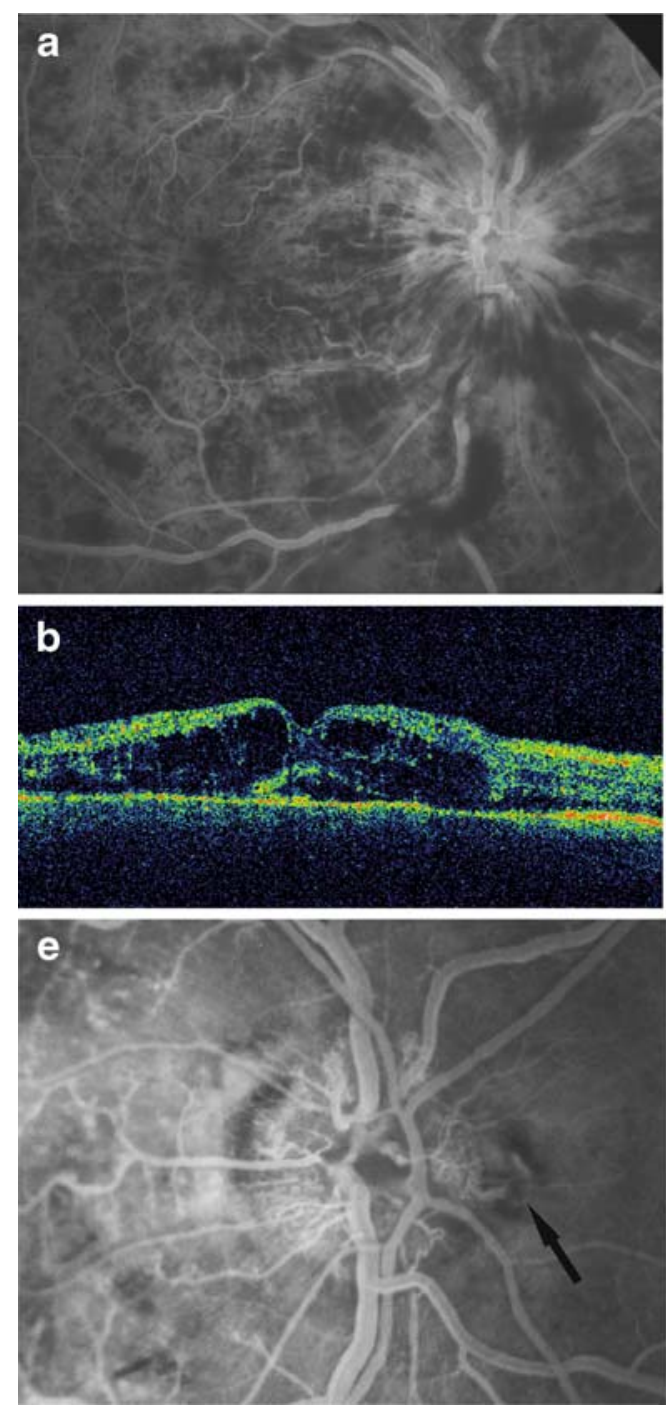
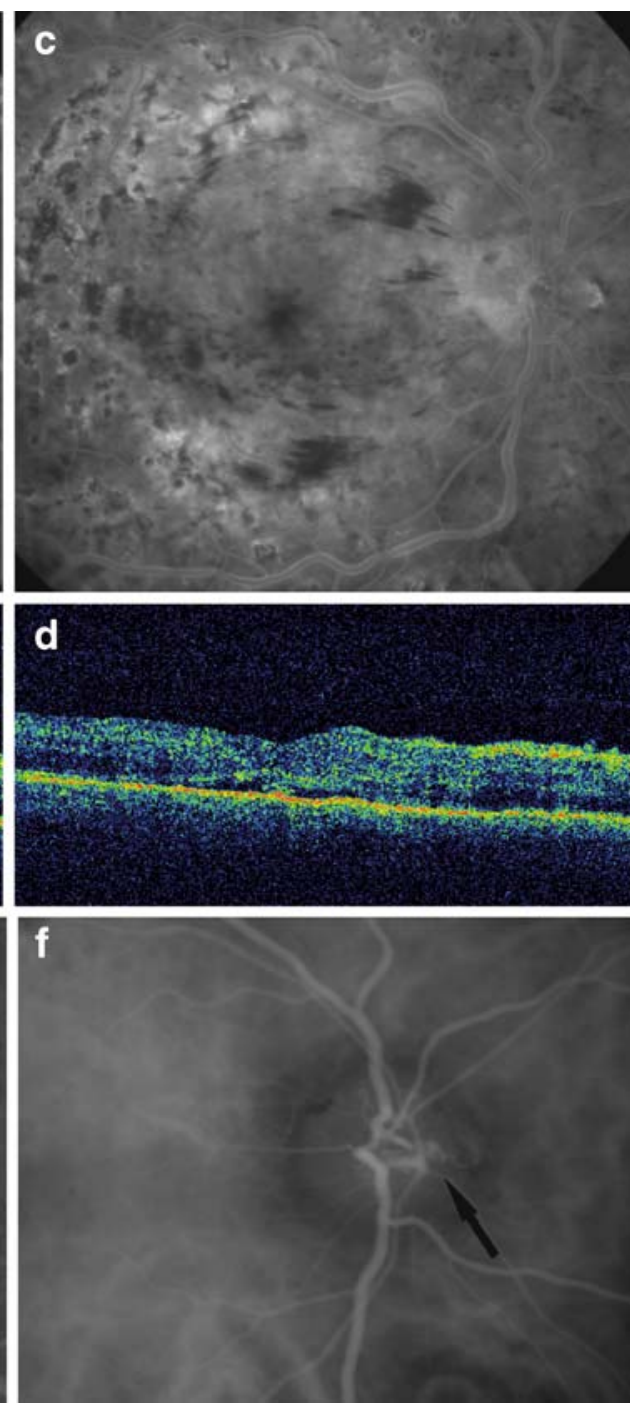
Fig. 2 Patient 5. a Preoperative fluorescein angiography showing macular edema and venous stasis secondary to central retinal vein occlusion. b Preoperative optical coherence tomography indicates a foveal thickness of $1.100 \mu \mathrm{m}$. Preoperative VA was 2.0 (LogMar). c Postoperative fluorescein angiography showing resolution of the venous dilation and tortuosity, and hemorrhage. d Postoperatively, foveal thickness decreased to $250 \mu \mathrm{m}$ with partial resolution of the edema. Postoperative VA was 0.7 (LogMar). e Fluorescein angiography 4 months after surgery showed the anastomosis at the nasal RON site (arrow)
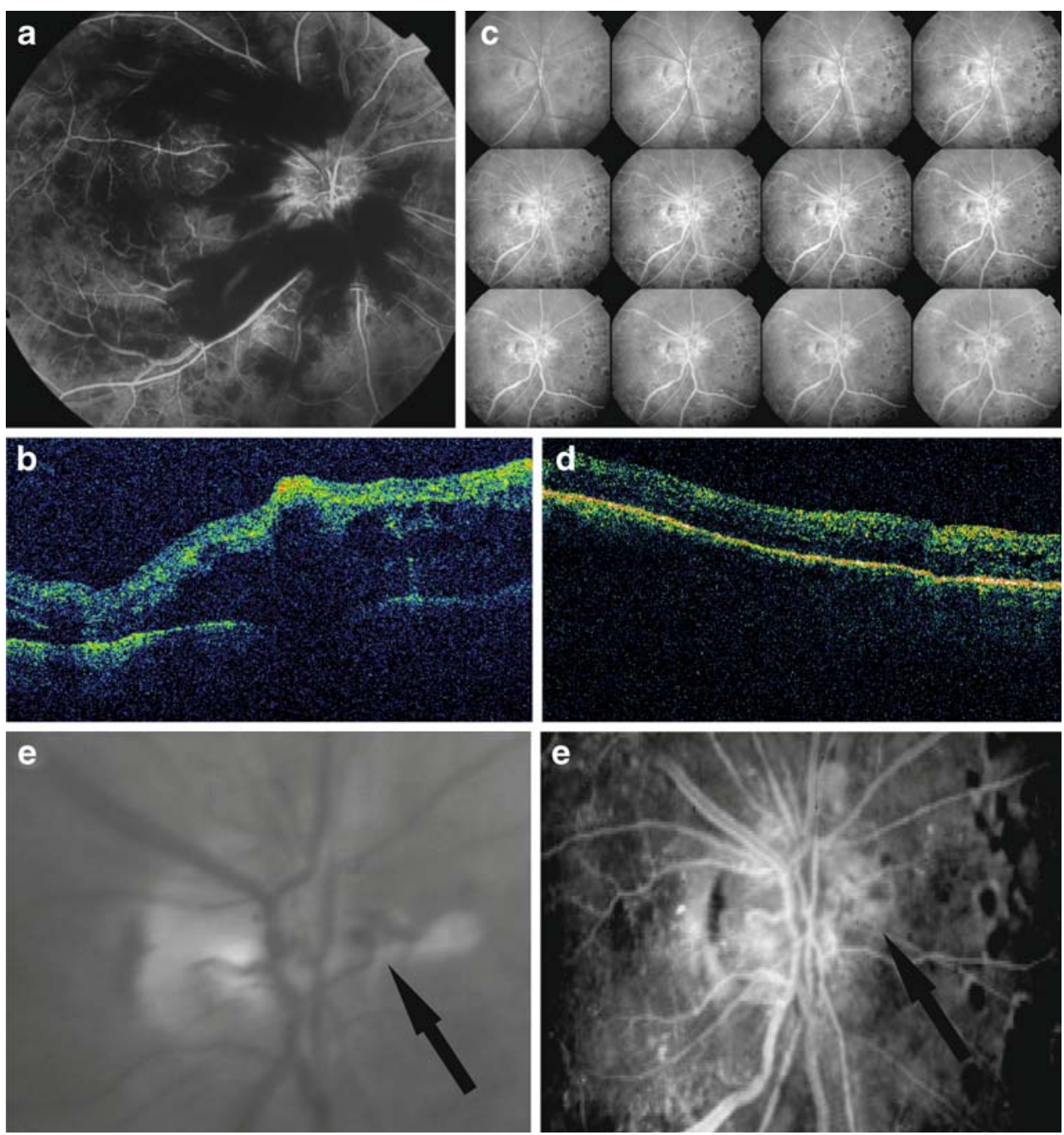

2-3 weeks with marked improvement of VA, but incomplete normalization of the retinal foveal thickness as measured by OCT (approximately $270 \mu \mathrm{m}$ ).

In the remaining four of these 13 patients (31\%), reperfusion did not occur immediately, but occurred later, with collateral vessel formation that appeared at the RON incision site in the venous phase of fluorescein angiography (Figs. 1e, 2e, and 3e) within 4 months after surgery. Macular edema also recurred in these patients, and a grid laser treatment was performed in all of them, but OCT revealed complete recovery of the foveal thickness (about $250 \mu \mathrm{m}$ ) in only one of these patients, and only a partial decrease in foveal retinal thickness (about $270 \mu \mathrm{m}$ ) in the other three (Table 1). All ten patients experienced a small subretinal hemorrhage at the RON site which disappeared during the 1-year follow-up. No visual field defects attributable to the RON procedure were observed in any of the patients.

In the preoperative and postoperative fluorescein angiography and OCT results, none of the patients experienced complications such as vitreous hemorrhage, increased intraocular pressure, endophthalmitis, and retinal detachment.

\section{Discussion}

Without treatment, the natural course of the disease will result in a significant visual handicap. CRVO is therefore considered the third most common vascular retinal disease that leads to blindness [10]. According to the Central Vein Occlusion Study Group [12], macular edema responds anatomically to grid photocoagulation, but has no efficacy in the improvement of visual acuity. Panretinal photocoagulation decreases the neovascular complications of CRVO [13]. Hemodilution therapy, even for non-ischemic retinal vein occlusion, was reported in the literature by several studies in which visual acuity seemed to improve after this therapy [14-16].

In the present study, the patients in whom reperfusion occurred within 2 weeks after surgery $(6 / 13,46 \%)$ obtained 
Fig. 3 Patient 6. a Preoperative fluorescein angiography showing extensive intraretinal hemorrhages and venous turgidity. $\mathbf{b}$ Preoperative foveal thickness measured by optical coherence tomography was $750 \mu \mathrm{m}$. Preoperative VA was 0.7 (LogMar). c Postoperative fluorescein angiography showing resolution with normal retinal vasculature. $\mathbf{d}$ Postoperative foveal thickness was $270 \mu \mathrm{m}$. Postoperative VA was -0.1 (LogMar). e Fundus photograph 4 months after surgery showed anastomosis at the nasal incision site (arrow)
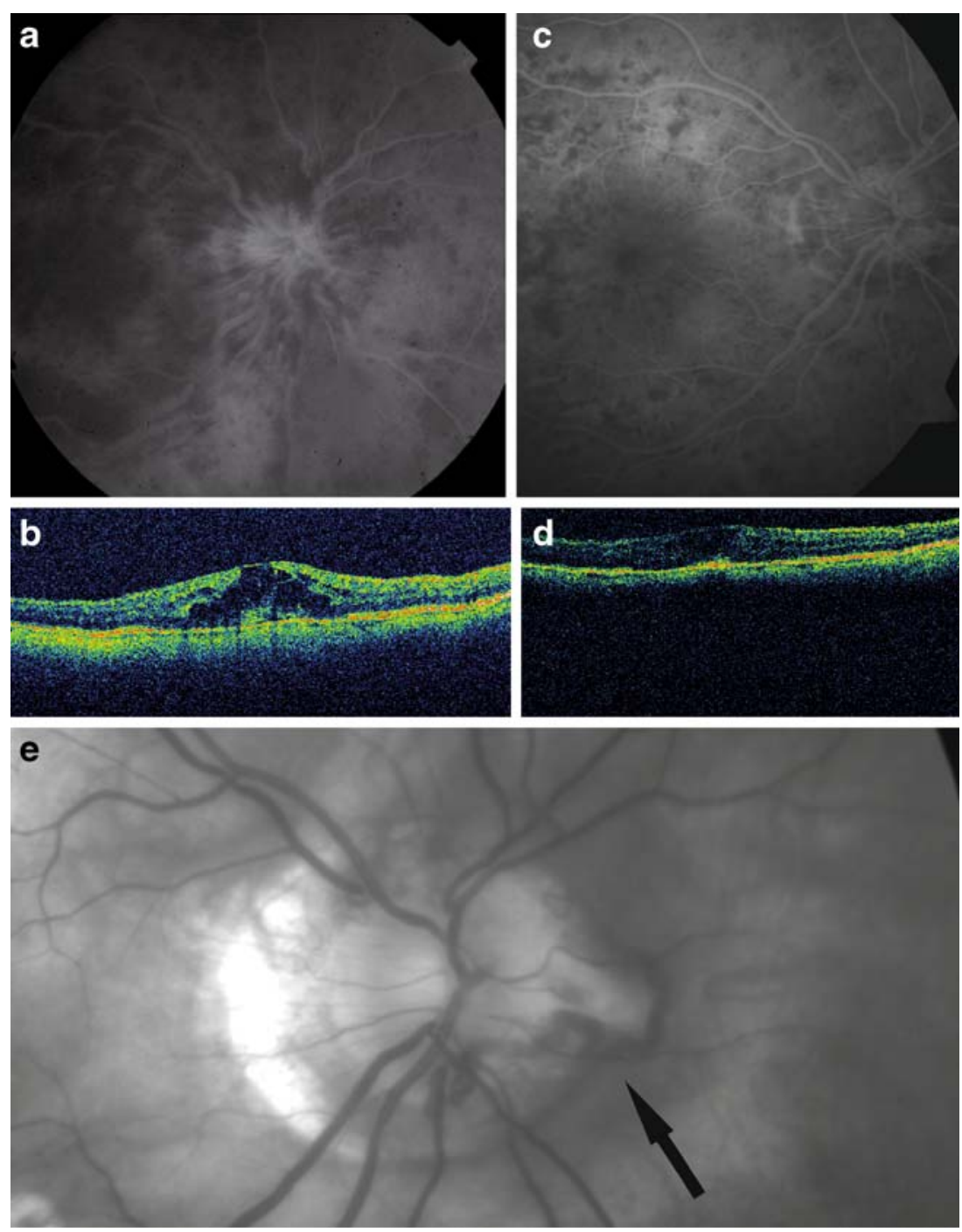

anatomic resolution in OCT and FAG and a functional recovery. These $6 / 13(46 \%)$ patients gained at least two Snellen lines. Meanwhile, in 4/13 patients (31\%) whose reperfusion took place after 4 months but with anastomosis, the final visual result has been even better, with an average improvement of five Snellen lines. Opremcak shows an improvement of three or more Snellen lines [17] and Arumi's outcomes were of one or two Snellen lines but in a wider series [18]. Thus, compared with the natural course of CRVO, the effects of RON are beneficial. We obtained a $77 \%$ (10/13) reperfusion rate and acute regression of macular edema in all 13 cases $(100 \%)$. This is probably due to the prompt but temporary anti-edemagenic action of triamcinolone [19-21] and its effect in preserving macular function until reperfusion occurs; this we observe in CRVO treated only with intravitreal triamcinolone. However, macular thickness values in these $3 / 13$ patients without reperfusion were increased again at a 1-year follow-up, as shown in Table 1. Vitrectomy alone, without ILM peeling at the posterior pole, in retinal occlusions, does not seem to be able to accomplish a complete resolution of edema, with uncertain results $[22,23]$.

The recurrence of macular edema appears to be related to depletion of the effect of triamcinolone; in these cases we performed grid laser treatment on the posterior pole. In the current study no significant correlation was found between VA and occlusion onset timing in the ten reperfused patients, but the correlation was significant only in five patients (of these ten) that showed a visual recovery useful for reading because the blood-retinal barrier had not yet suffered permanent damage.

None of the patients developed neovascular glaucoma, probably due to reperfusion and removal of the vitreous gel that mediates the retinal or iris neovascularization. Thus, this surgical procedure might limit the extent of retinal ischemia and its complications.

VA recovery was dependent on the retinal thickness examined by OCT. Good VA was maintained if retinal 
Table 1 Demographic data of 13 patients with ischemic nonperfused central retinal vein occlusion (CRVO) for 1-year follow-up

\begin{tabular}{|c|c|c|c|c|c|c|c|}
\hline \multirow[t]{2}{*}{ Patients (no./sex/ age/eye) } & \multirow{2}{*}{$\begin{array}{l}\text { Occlusion onset } \\
\text { (days, months) }\end{array}$} & \multicolumn{2}{|c|}{ ETDRS VA(LogMAR) } & \multicolumn{2}{|c|}{ OCT $(\mu \mathrm{m})$} & \multirow{2}{*}{$\begin{array}{l}\text { Laser } \\
\text { (Yes-No) }\end{array}$} & \multirow{2}{*}{$\begin{array}{l}\text { Anastomosis Formatior } \\
\text { (Yes-No) }\end{array}$} \\
\hline & & Pre & Post & Pre & Post & & \\
\hline $1 / \mathrm{F} / 61 / \mathrm{R}$ & 23 days & 2.0 & 1.0 & 1.120 & 350 & Yes & No \\
\hline $2 / \mathrm{F} / 71 / \mathrm{L}$ & 20 days & 0.4 & -0.3 & 350 & 270 & Yes & Yes \\
\hline $3 / \mathrm{M} / 74 / \mathrm{R}$ & 4 months & 0.7 & -0.1 & 920 & 270 & Yes & Yes \\
\hline $4 / \mathrm{M} / 74 / \mathrm{R}$ & 2 months & 0.4 & 0.3 & 400 & 270 & No & No \\
\hline $5 / \mathrm{M} / 78 / \mathrm{R}$ & 8 months & 2.0 & 0.7 & 1.100 & 250 & Yes & Yes \\
\hline $6 / F / 75 / R$ & 4 months & 0.7 & -0.1 & 750 & 270 & Yes & Yes \\
\hline $7 / \mathrm{M} / 76 / \mathrm{L}$ & 4 months & 1.0 & 0.2 & 960 & 340 & Yes & No \\
\hline $8 / \mathrm{F} / 63 / \mathrm{L}$ & 8 months & 1.0 & 1.0 & 1.000 & 1,000 & No & No \\
\hline 9/F/71/R & 8 months & 1.0 & 0.7 & 900 & 270 & No & No \\
\hline $10 / \mathrm{F} / 62 / \mathrm{L}$ & 4 months & 1.0 & 1.0 & 980 & 970 & No & No \\
\hline $11 / \mathrm{F} / 68 / \mathrm{L}$ & 1 month & 0.4 & -0.2 & 390 & 270 & No & No \\
\hline $12 / \mathrm{F} / 76 / \mathrm{L}$ & 4 months & 0.7 & 0.0 & 850 & 310 & Yes & No \\
\hline $13 / \mathrm{M} / 58 / \mathrm{R}$ & 2 months & 0.7 & 0.7 & 830 & 800 & No & No \\
\hline
\end{tabular}

$\mathrm{M}=$ Male

$\mathrm{F}=$ Female

$\mathrm{R}=$ Right eye

$\mathrm{L}=$ Left eye

$\mathrm{VA}=$ Visual acuity (LogMAR units) with ETDRS chart

OCT $=$ Optical coherence tomography (foveal thickness)

thickness in the macular area was approximately $270 \mu \mathrm{m}$. Therefore, an increase in VA was significantly correlated with a decrease in macular edema. Further, VA improvement seemed to be correlated with the onset of occlusion (the more recent the occlusion, the better the VA recovery).

Although three $(23 \%)$ of the 13 patients did not achieve reperfusion, ten $(77 \%)$ of the 13 obtained adequate retinal

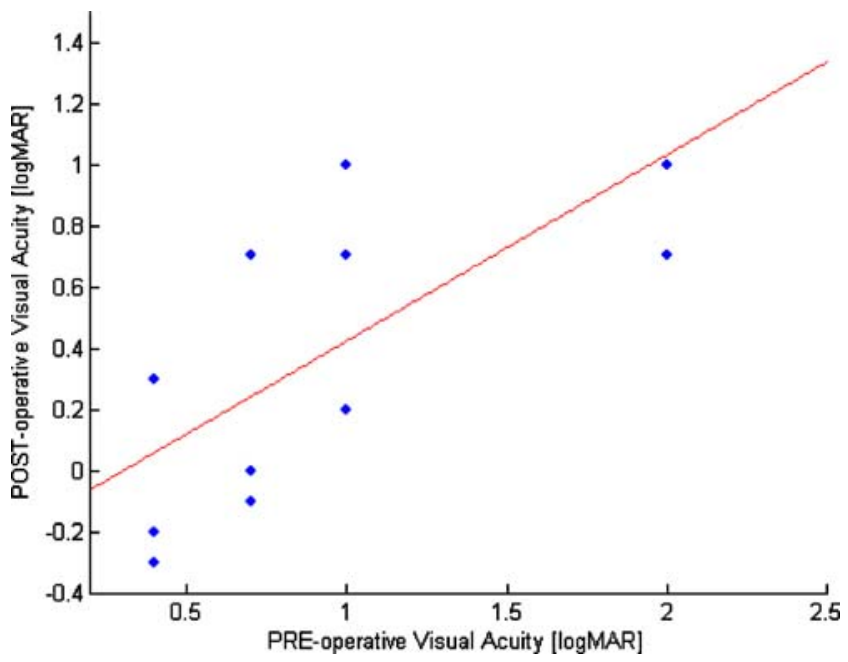

Fig. 4 Scatter plot of the pre- and post-operative values of Snellen Visual Acuity (the regression line showed is for illustrative purpose only) reperfusion. In six $(46 \%)$ of these 13 , reperfusion developed within 2 weeks after surgery, with verified vessel decompression. In four (31\%) of the 13 , reperfusion developed within 4 months, but with collateral vessel formation, consistent with the report by Arumi et al. [18].

The mechanisms underlying the development of collateral vessels in these four patients may be related to accelerated

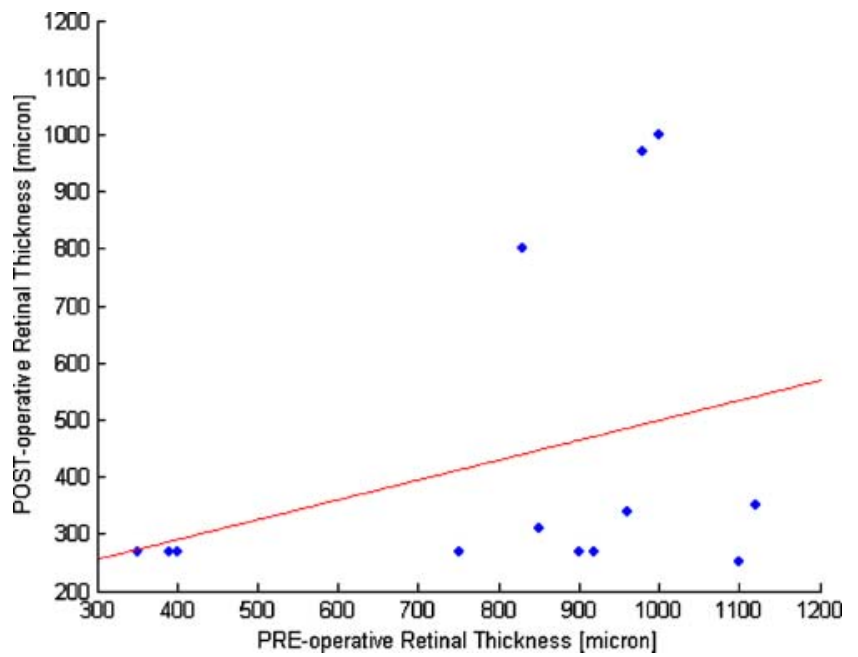

Fig. 5 Scatter plot showing the pre and post-operative values of retinal thickness $(\mu \mathrm{m})$ 
development of the retinochoroidal collateral routes induced by RON. In fact, according to Takahashi [24], the natural time course of CRVO ranges from 1.0 to 9.3 years (mean 3.6 years), and papillary vascular loops appeared to connect the retinal veins and choroidal veins in ten of the 13 eyes.

Recovery of VA and prognosis in patients with new collateral formation were better than that in patients who did not develop any vascular formations. The fluorescein angiography results indicated that normalization of retinal thickness improved postoperative functional recovery (Table 1).

We think that the retinal reperfusion and the improvement of VA in our patients were caused by the release of central vein compression through the cut at the cribriform plate and the scleral outlet, which increased the venous outflow and retinal circulation, and by the development of a new anastomosis, which allowed the blood to drain. In fact, the presence of collateral circulation suggested that capillary draining occurred at the macular level.

These results suggest that RON is a low-risk alternative therapy, but a randomized study with a larger number of patients is necessary to establish the factors important for developing collateral circulation that allows for blood drainage beyond the occluded vessel.

Open Access This article is distributed under the terms of the Creative Commons Attribution Noncommercial License which permits any noncommercial use, distribution, and reproduction in any medium, provided the original author(s) and source are credited.

\section{References}

1. The Eye Disease Case-Control Study Group (1996) Risk factors for central retinal vein occlusion. Arch Ophthalmol 114:545-554

2. Rath EZ, Frank RN, Shin DH, Kim C (1992) Risk factors for retinal vein occlusions: a case-controlled study. Ophthalmology 99:509-514

3. Hayreh SS (1994) Retinal vein occlusion. Indian J Ophthalmol 42:109-132

4. Hayreh SS (2005) Prevalent misconceptions about acute retinal vascular occlusive disorders. Prog Retin Eye Res 24:493-519

5. Green WR, Chan CC, Hutchins GM, Terry JM (2005) Central retinal vein occlusion: a prospective histopathologic study of 29 eyes in 28 cases. Retina 25:27-55

6. Opremcak EM, Bruce RA, Lomeo MD et al (2001) Radial optic neurotomy for central vein occlusion. Retina 21:408-415

7. Opremcak EM, Rehmar AJ, Ridenour CD, Kurz DE (2006) Radial optic neurotomy for central retinal vein occlusion. Retina 26:297-305
8. The Central Vein Occlusion Study Group (1997) Natural history and clinical management of central retinal vein occlusion. Arch Ophthalmol 115:486-491

9. The Central Vein Occlusion Study Group N report (1995) A randomized clinical trial of early panretinal photocoagulation for ischemic central vein occlusion. Ophthalmology 102:14341444

10. The Central Vein Occlusion Study Group (1993) Baseline and early natural history report: the central vein occlusion study. Arch Ophthalmol 111:1087-1095

11. Jonas JB, Kreissig I, Degenring RF (2002) Intravitreal triamcinolone acetonide as treatment of macular edema in central retinal vein occlusion. Graefes Arch Clin Exp Ophthalmol 240(9):782783

12. The Central Vein Occlusion Study Group M Report (1995) Evaluation of grid pattern photocoagulation for macular edema in central vein occlusion. Ophthalmology 102:1425-1433

13. Laatikainen L, Kohner EM, Khoury D, Blach RK (1977) Panretinal photocoagulation in central retinal vein occlusion: a randomized controlled clinical study. Br J Ophthalmol 61:741-753

14. Glacet-Bernard A, Zourdani A, Milhoub M, Maraqua N, Coscas G, Soubrane G (2001) Effect of isovolemic hemodilution in central retinal vein occlusion. Graefes Arch Clin Exp Ophthalmol 239:909 914

15. Hansen LL, Wiek J, Wiederholt M (1989) A randomised prospective study of treatment of non-ischaemic central retinal vein occlusion by isovolaemic haemodilution. $\mathrm{Br} \mathrm{J}$ Ophthalmol 73:895-899

16. Wolf S, Arend O, Bertram B, Remky A, Schulte K, Wald KJ, Reim M (1994) Hemodilution therapy in central retinal vein occlusion. One-year results of a prospective randomized study. Graefes Arch Clin Exp Ophthalmol 232(1):33-39

17. Opremcak EM, Rehmar AJ, Ridenour CD, Kurz DE, Borkowski LM (2006) Radial optic neurotomy with adjunctive intraocular triamcinolone for central retinal vein occlusion: 63 consecutive cases. Retina 26:306-313

18. Garcia-Arumi J, Boixedera A, Martinez-Castillo V, Castillo R, Dou A, Corcostegui B (2003) Chorioretinal anastomosis after radial optic neurotomy for central retinal vein occlusion. Arch Ophthalmol 121:1385-1391

19. Greenberg PB, Martidis A, Rogers AH, Duker JS, Reichel E (2002) Intravitreal triamcinolone acetonide for macular oedema due to central retinal vein occlusion. Br J Ophthalmol 86:247-248

20. Park CH, Jaffe GJ, Fekrat S (2003) Intravitreal triamcinolone acetonide in eyes with cystoid macular edema associated with central retinal vein occlusion. Am J Ophthalmol 136:419-425

21. Ip MS, Gottlieb JL, Kahana A, Scott IU, Altaweel MM, Blodi BA, Gangnon RE, Puliafito CA (2004) Intravitreal triamcinolone for the treatment of macular edema associated with central retinal vein occlusion. Arch Ophthalmol 122:1131-1136

22. DeCroos FC, Shuler RK Jr, Stinnett S, Fekrat S (2009) Pars plana vitrectomy, internal limiting membrane peeling, and panretinal endophotocoagulation for macular edema secondary to central retinal vein occlusion. Am J Ophthalmol 147(4):627-633

23. Mandelcorn MS, Mandelcorn E, Guan K, Adatia FA (2007) Surgical macular decompression for macular edema in retinal vein occlusion. Can J Ophthalmol 42(1):116-122

24. Takahashi K, Muraoka K, Kishi S, Shimizu K (1998) Formation of retinochoroidal collaterals in central retinal vein occlusion. Am J Ophthalmol 126:91-99 